\title{
Putting positive psychology to work in organisations
}

\author{
Kevin Money \\ Associate Professor, Director of The John Madejski Centre for Reputation, Henley Business \\ School, University of Reading
}

\section{Carola Hillenbrand}

Subject Area Leader, Reputation and Relationships, Henley Business School, University of Reading

\author{
Nuno da Camara \\ Research Fellow, The John Madejski Centre for Reputation, \\ Henley Business School, University of Reading
}

\begin{abstract}
This article takes positive psychology concepts from the domain of individual psychology and applies them to the workplace. The adaptation of the Approaches to Happiness Questionnaire (Seligman, 2002), developed by Martin Seligman, suggests that the three dimensions of pleasure, engagement and meaning are relevant to employees in the organisational context. In addition, Seligman's (2002) classification of Character Strengths and Virtues is explored and their relevance for workplace performance is discussed. The paper concludes by suggesting that positive psychology is a useful lens through which approaches to work and employee potential can be explored further and suggests some future research in the area.
\end{abstract}

\section{Introduction}

Since its inception at the beginning of this century, the positive psychology movement has generated a significant following amongst academics and management practitioners alike. It is led by former president of The American Psychological Association, Professor Martin Seligman. A key belief of positive psychology is that for a long time, psychology has focused principally on understanding mental illness and dysfunctional behaviour. Whilst this line of enquiry has provided significant benefits for people suffering from psychological distress, it is the view of positive psychologists that important insights into the study of psychological health can be achieved by studying the positive side of human experience. Positive psychology research has concentrated on understanding people's lives and the factors that are associated with life satisfaction. Surveys have compared the happiness of individuals in different countries and cultures and at different stages of life. A key finding is that beyond the threshold of a safety net, money adds little to subjective wellbeing (Seligman, 2002, p. 165). As Seligman (2002, p. 166) explains, we are 
experiencing the change from a money-based economy to a "satisfaction economy" in which people increasingly make decisions on what makes them satisfied and happy, not just financially better off. To date, positive psychology has been applied mostly in clinical psychology and educational settings. Yet there is still a relative paucity of research which applies the positive psychology metaphor directly to organisations and the workplace. The aim of this article is to address this imbalance and suggest the potential uses of positive psychology in organisations and a future research agenda. This article is structured into three main sections. Section 1 gives a summary of the key concepts from the positive psychology literature. Section 2 provides examples of the application of positive psychology concepts to the workplace. Finally, Section 3 provides a discussion of these examples and suggests areas for future research.

\section{Section I}

\section{What is positive psychology?}

Positive psychology is the study of the conditions and processes that contribute to the flourishing or optimal functioning of people, groups and institutions (Gable and Haidt, 2005). It champions the development of positive emotions and the fulfilment of human potential (Gable and Haidt, 2005; Seligman and Csikszentmihalyi, 2000). As Seligman and Csikszentmihalyi (2000) explain, the mission of positive psychology is to focus more attention on the study of strength and virtue and not just the study of pathology, weakness and damage. Thus, positive psychology is about nurturing what is best in human nature and not solely fixing what is broken. It applies the scientific method to researching areas beyond the traditional remit of health and illness, such as work, education, insight, love, growth and play (Seligman and Csikszentmihalyi, 2000). Similarly, as Luthans (2002) explains, the purpose of positive psychology is to shift the emphasis away from studying only the worst things in life to studying some of the best things in life and to build a scientific theory base around the factors that allow individuals, groups, organisations and communities to thrive and prosper. In their research, positive psychologists are concerned with "valued subjective experiences: wellbeing, contentment and satisfaction (in the past); hope and optimism (for the future); and flow and happiness (in the present)" (Seligman and Csikszentmihalyi, 2000).

Historically, the positive psychology movement is rooted in the writings of humanistic psychologists like Abraham Maslow, Carl Rogers, Rollo May and Victor Frankl whose interests lay in the positive features of human functioning and people's experience of optimism, joy, altruism and meaning in their lives (Gable and Haidt, 2005; Fineman, 2006). Indeed, as Roberts (2006) points out, Maslow's book on Motivation and Personality (1954) included a chapter entitled "Toward a Positive Psychology". Maslow's work around selfactualisation provides an early foundation for many of the concepts developed in positive psychology, although Seligman and his co-authors have often downplayed this link, most probably as a result of the humanistic psychology movement's failure to develop an empirically sound research base (Seligman 
and Csikszentmihalyi, 2000). In contrast to that, the current positive psychology movement is firmly focused on scientific measurement and evidencebased research (Fineman, 2006). On the subject of work, to which this article is dedicated, the links between Maslow and Seligman's writings are striking. Maslow (1971, p. 42) wrote, for example, that:

"Self-actualizing people are, without one single exception, involved in a cause outside their own skin, in something outside of themselves. They are devoted, working at something, something which is very precious to themsome calling or vocation in the old sense, the priestly sense. They are working at something which fate has called them to somehow and which they work at and which they love, so that the work-joy dichotomy in them disappears."

Similarly, Seligman (2002, p. 166) states that "a calling is the most satisfying form of work because, as a gratification, it is done for its own sake rather than for the material benefits it brings". In the 1990s, positive psychology developed its original 'three pillars' approach to studying positive human functioning (Gable and Haidt, 2005). According to this approach, positive psychology is fundamentally about the study of positive subjective experience or what we more commonly understand as positive emotion, which is one pillar. On a social psychological level there is a separate pillar concerned with positive institutions and communities and how these foster and develop positive emotions and traits amongst individuals (Seligman and Czikszentmihalyi, 2000). Lastly, another pillar focuses on examining positive individual characteristics or traits, which can be understood as human strengths and virtues. As Gable and Haidt (2005) explain, research and interventions into the first and third pillar have been much more successful than research into positive social institutions and communities and attempts to improve the functioning of schools, governments and places of work.

\section{Positive psychology and work: the studies to date}

Organisational behaviourists have recently applied the concepts of positive psychology to the study of organisations focusing on positiveness and the understanding of what is best in the human condition, which has led to the study of so called "positive deviance" and "spirals of flourishing" (Fineman, 2005; Cameron, Dutton and Quinn, 2003). At the heart of this approach lies the emergent knowledge that happiness is causal and brings many benefits since happy people are healthier, more successful and more socially engaged, and the causal direction runs both ways (Lyubomirsky, King and Diener, 2005). The inherent assumption in the development of positiveness in organisations is that humans have an intrinsic desire to self-realise and to express their capacities to the fullest extent, being all too ready to connect positively and sociably with the world, given the right opportunity (Fineman, 2005).

As with positive psychology, the development of positive organisational scholarship has emerged as a response to psychologists' preoccupation with the negative and pathological in the study of human behaviour (Fineman, 2005; Seligman, 1999; Seligman and Pawelski, 2003). In organisations the 
objective is to find ways of "unlocking capacities for ... meaning creation, relationship transformation, positive emotion cultivation and high-quality connections" (Cameron, Dutton and Quinn, 2003). As Fineman (2005) explains:

"At first blush, the positive turn offers a seductive discourse, with much promise. It presents a broad vision of the sunnier side of life, where positiveness can be harnessed for noble individual and organisational ends. It takes over, claim its proponents, where "positive thinking" gurus leave off, by applying rigorous scientific method to the folk nostrums of positivity."

Luthans (2002) has developed the concept of positive organisational behaviour (POB) as "the study and application of positively oriented human resource strengths and psychological capacities that can be measured, developed, and effectively managed for performance improvement in today's workplace". In this context, positive organisational behaviour is seen as being founded in state-like factors in human behaviour, moving away from the more fixed, trait-like personality, attitudinal, and motivational variables traditionally associated with Organisational Behaviour as a subject (Luthans, 2002). Inspired by positive psychology's focus on positive emotion, one of the pillars of Seligman and Csikszentmihalyi's (2000) theory, positive organisational behaviour is strongly developmental in its approach and focuses on encouraging the more positive aspects of human nature to improve workplace performance. Luthans (2002) thus emphasises the five key attributes outlined in his CHOSE model, namely confidence, hope, optimism, subjective wellbeing and emotional intelligence - and sends a powerful message to the field and to organisations in general that it is time to move away from the study of dysfunctional behaviour and workplace problems.

While theorists in organisational behaviour focus much upon developing theory within the positive emotion pillar of positive psychology, the research presented in this paper goes further by contributing to the other two pillars of positive psychology, namely the study of positive institutions and the study of positive individual characteristics or traits, in application to a work environment. The paper's contribution to positive psychology at work is made in three ways. Firstly, it provides much needed empirical evidence to the field of positive psychology at work. Secondly, the study of positive institutions is researched by investigating how different approaches to work can impact on outcomes such as job satisfaction and commitment. Thirdly, it focuses on exploring the value of positive individual characteristics or traits, specifically in the context of leveraging human strengths and virtues at work and matching them with the perceived demands of work.

\section{Applying positive psychology to the workplace}

Positive psychology research is focused on uncovering the roots and causes of long-term happiness. The consideration of positive psychology in the work context raises some interesting questions about the relationship between satisfaction in life and at work. How does work contribute or take away from 
individual happiness? And, can organisations use learnings from positive psychology to enhance employee wellbeing and performance? We explore these wider questions by applying two of Seligman's questionnaires to the work context and discuss the results.

\section{Putting positive institutions to work: approaches to happiness}

Seligman (2002) suggests that individual happiness depends upon three approaches to life. All three of these approaches can be important to longterm life satisfaction and need to be nurtured and balanced to maintain happiness. The three approaches are:

- The Pleasant Life - the pursuit of tangible pleasures.

- The Engaged Life - engagement and taking an interest in activities, learning and growing.

- The Meaningful Life - the pursuit of and involvement in something bigger than yourself in the service of an overall purpose or meaning.

Recent research in positive psychology suggests that it is possible to distinguish and measure these different approaches (Peterson, Park and Seligman, 2005b). Furthermore, the research suggests that the happiest or most satisfied people are those that direct their pursuits towards a balance of all three approaches, particularly if they develop a sense of the engaged and meaningful lives (Peterson, Park and Seligman, 2005b). A major tenet of positive psychology is therefore the distinction between short-term pleasure and long-term enjoyment or satisfaction as expressed through engagement and meaning. Thus, as Seligman and Csikszentmihalyi (2000) explain:

"Pleasure is the good feeling that comes from satisfying homeostatic needs such as hunger, sex, and bodily comfort. Enjoyment, on the other hand, refers to the good feelings people experience when they break through the limits of homeostasis - when they do something that stretches them beyond what they were-in an athletic event, an artistic performance, a good deed, a stimulating conversation. Enjoyment, rather than pleasure, is what leads to personal growth and long-term happiness."

Seligman and Csikszentmihalyi (2000) favour the pursuit of the engaged and meaningful lives over the pleasant life and suggest that this is what leads to longer-term happiness. If the findings of positive psychology hold true in the workplace, then the experience of engaging and meaningful work is likely to result in more sustained happiness amongst employees. The benefits of developing engagement and meaning at work would be all the more justified from an organisational point of view if it can be shown that in addition to long-term satisfaction, such work is also associated with other performance orientated outcomes such as employee commitment. The establishment of a link between engagement and meaning at work and key drivers of organisational performance is likely to encourage organisations to act as positive institutions and focus on the development of these positive features in employees' work. 
Table 1: Classification of 6 virtues and 24 character strengths (Peterson and Seligman, 2004)

\begin{tabular}{|c|c|}
\hline \multicolumn{2}{|c|}{ Virtue and strength definition } \\
\hline $\begin{array}{l}\text { Wisdom and } \\
\text { knowledge } \\
\text { Creativity } \\
\text { Curiosity } \\
\text { Open-mindedness } \\
\text { Love of learning } \\
\text { Perspective }\end{array}$ & $\begin{array}{l}\text { Cognitive strengths that entail the acquisition and use of } \\
\text { knowledge } \\
\text { Thinking of novel and productive ways to do things } \\
\text { Taking an interest in all of ongoing experience } \\
\text { Thinking things through and examining them from all sides } \\
\text { Mastering new skills, topics, and bodies of knowledge } \\
\text { Being able to provide wise counsel to others }\end{array}$ \\
\hline $\begin{array}{l}\text { Authenticity } \\
\text { Bravery } \\
\text { Persistence } \\
\text { Zest }\end{array}$ & $\begin{array}{l}\text { Emotional strengths that involve the exercise of will to } \\
\text { accomplish goals in the face of opposition, external or internal } \\
\text { Speaking the truth and presenting oneself in a genuine way } \\
\text { Not shrinking from threat, challenge, difficulty, or pain } \\
\text { Finishing what one starts } \\
\text { Approaching life with excitement and energy }\end{array}$ \\
\hline Humanity & $\begin{array}{l}\text { Interpersonal strengths that involve 'tending and befriending' } \\
\text { others }\end{array}$ \\
\hline $\begin{array}{l}\text { Kindness } \\
\text { Love } \\
\text { Social intelligence }\end{array}$ & $\begin{array}{l}\text { Doing favours and good deeds for others } \\
\text { Valuing close relations with others } \\
\text { Being aware of the motives and feelings of self and others }\end{array}$ \\
\hline $\begin{array}{l}\text { Justice } \\
\text { Fairness } \\
\text { Leadership } \\
\text { Teamwork }\end{array}$ & $\begin{array}{l}\text { Civic strengths that underlie healthy community life } \\
\text { Treating all people the same according to notions of fairness and } \\
\text { justice } \\
\text { Organising group activities and seeing that they happen } \\
\text { Working well as member of a group or team }\end{array}$ \\
\hline $\begin{array}{l}\text { Temperance } \\
\text { Forgiveness } \\
\text { Modesty } \\
\text { Prudence } \\
\text { Self-regulation }\end{array}$ & $\begin{array}{l}\text { Strengths that protect against excess } \\
\text { Forgiving those who have done wrong } \\
\text { Letting one's accomplishments speak for themselves } \\
\text { Being careful about one's choices; not saying or doing things that } \\
\text { might later be regretted } \\
\text { Regulating what one feels and does }\end{array}$ \\
\hline Transcendence & $\begin{array}{l}\text { Strengths that forge connections to the larger universe and } \\
\text { provide meaning }\end{array}$ \\
\hline $\begin{array}{l}\text { Appreciation of beauty } \\
\text { and excellence }\end{array}$ & $\begin{array}{l}\text { Noticing and appreciating beauty, excellence, and/or skilled } \\
\text { performance all domains of life }\end{array}$ \\
\hline $\begin{array}{l}\text { Gratitude } \\
\text { Hope } \\
\text { Humour } \\
\text { Religiousness }\end{array}$ & $\begin{array}{l}\text { Being aware of and thankful for the good things that happen } \\
\text { Expecting the best and working to achieve it } \\
\text { Liking to laugh and tease; bringing smiles to other people } \\
\text { Having coherent beliefs about the higher purpose and meaning } \\
\text { of life }\end{array}$ \\
\hline
\end{tabular}




\section{Putting individual strengths to work: character strengths and virtues (CSV)}

Seligman and his co-authors have also developed a classification of Character Strengths and Virtues (CSV), which complements mental illness classifications like the Diagnostic and Statistical Manual of Mental Disorders (e.g. American Psychiatric Association, 1994), and present some cross-cultural findings that suggest a surprising ubiquity of strengths and virtues across the world (Park, Peterson and Seligman, 2005a). Table 1 (opposite) lays out the classification, which includes the six virtues and 24 strengths of character. The CSV describes and classifies strengths and virtues that enable human thriving and relies on six overarching virtues that almost every culture across the world endorses: wisdom, courage, humanity, justice, temperance and transcendence (Seligman, Steen, Park and Peterson, 2005). Furthermore, the definition of a character strength is that it is a personality trait that contributes to individual fulfillment and the research shows that emotional heartfelt strengths - zest, gratitude, hope and love - are more robustly associated with life satisfaction than are the more cerebral strengths such as curiosity and love of learning (Park, Peterson and Seligman, 2004). Park et al., (2005b) find longitudinal evidence also that these 'heartfelt' strengths foreshadow subsequent life satisfaction.

The definition and measurement of strengths and virtues makes it possible to investigate the role that they play in the workplace. The basic proposition is that life satisfaction will be maximised when an individual lives a life that provides an outlet for their strengths and virtues. Considering that people spend a large portion of their lives at work, it follows that this thesis should hold in the workplace too. Thus, in the context of work, we suggest that job satisfaction (and its associated benefits) should flow from finding a match between ones strengths and the opportunities to express these in a job. This paper sets out to test this thesis in the workplace. The paper also investigates the extent to which there is a match between the skills and virtues that individuals possess and the perceived demands of the workplace.

\section{Section 2}

\section{Applied examples of putting positive psychology to work}

It is necessary to understand whether the concepts identified in the wider study of positive psychology can reliably and usefully be applied in the workplace. The following two studies show how positive psychology concepts are applied to the workplace.

\section{Summary of Study I: Customising the approaches to happiness questionnaire to the work context}

The first study explores whether the approaches to happiness questionnaire can be adapted specifically to the workplace. The logic for this is simple: if work forms an important and time-consuming part of life, then surely 
individuals will pursue similar approaches in their work as they do in their lives in general. More specifically, this paper questions whether the pursuit of pleasure, engagement and meaning in work are important in the development of work satisfaction, just like the pursuit of these elements in life is associated with life satisfaction. In addition the authors investigate whether organisational commitment is associated with having these different approaches to work.

\section{Summary of Study 2: Adapting the strengths and virtues approach to develop a measure of strength expression and match in the work context}

The second study adapts Seligman's (2002) strengths and virtues questionnaire, to measure the expression of strengths and virtues in the workplace and also to measure how employees perceive that these match with the requirements of the workplace. In his current work, Seligman's (2002) thesis is that life satisfaction is associated with living a life in which there is a match between the existence and expression of strengths. This study aims to explore the link between the existence and expression of strengths at work.

\section{Study I}

\section{Method and Results}

Seligman's Approaches to Happiness questionnaire was adapted from the context of life in general to the workplace. This resulted in a questionnaire with four to six items to measure each of the three areas of meaning, engagement and pleasure, which can be found in Table 2 below. The questionnaire also included measures of job satisfaction and commitment to work. After piloting and pre-testing, the questionnaire was administered to 341 professionals working in more than 30 different companies across both the profit and not for profit sector, ranging in geographical location from Continental Europe, the UK and Australia. This resulted in a total response of 208 and a response rate of over 60\%. Data was collected in 2008. After careful data examination addressing issues such as missing values, outliers and normality (Hair et al., 2005), data analysis included the following steps:

- An exploratory factor analysis of the items measuring approaches to work.

- Cronbach Alpha's Reliability checks for the emerging factors and creation of scales.

- Regression analysis linking approaches to work to two outcome factors commitment and work satisfaction.

The factor analysis for the approaches to work resulted in a three factor solution, which explained $56 \%$ of the variance. This is in line with theory and our expectations that the three distinct approaches to happiness can be expressed also in relation to work. Table 2 below shows factor loadings above 0.5 (Hair et al., 2005) and also reports on Cronbach Alpha's reliability scores for the three scales. The reported Cronbach Alpha scores are in line with Hair 
Table 2: Results of the exploratory factor analysis and Cronbach Alpha's Reliability scores

\begin{tabular}{|c|c|c|c|}
\hline & $\begin{array}{l}\text { Factor 1: } \\
\text { Meaning }\end{array}$ & $\begin{array}{c}\text { Factor 2: } \\
\text { Engagement }\end{array}$ & $\begin{array}{l}\text { Factor 3: } \\
\text { Pleasure }\end{array}$ \\
\hline My work has lasting meaning & 0.86 & & \\
\hline The work I do matters to society & 0.85 & & \\
\hline $\begin{array}{l}\text { Through the work that I do I have responsibility to } \\
\text { make the world a better place }\end{array}$ & 0.81 & & \\
\hline The work that I do serves a higher purpose & 0.76 & & \\
\hline $\begin{array}{l}\text { In choosing what I do at work, I take into account } \\
\text { whether it will benefit other people }\end{array}$ & 0.74 & & \\
\hline $\begin{array}{l}\text { I have spent a lot of time thinking about my work } \\
\text { and how it fits into the bigger picture of what life } \\
\text { means }\end{array}$ & 0.52 & & \\
\hline In my work I am always very absorbed in what I do & & 0.81 & \\
\hline $\begin{array}{l}\text { Regardless of what I am doing at work, time passes } \\
\text { very quickly }\end{array}$ & & 0.69 & \\
\hline $\begin{array}{l}\text { In my work I am rarely distracted by what is going } \\
\text { on around me }\end{array}$ & & 0.68 & \\
\hline $\begin{array}{l}\text { In my work, I am usually 'in a zone' and not } \\
\text { conscious of myself }\end{array}$ & & 0.67 & \\
\hline $\begin{array}{l}\text { In choosing what I do at work, I take into account } \\
\text { whether it will be pleasurable }\end{array}$ & & & 0.73 \\
\hline $\begin{array}{l}\text { For me, good work is simply work that is } \\
\text { pleasurable. }\end{array}$ & & & 0.67 \\
\hline In my work I love to do that which excites my senses & & & 0.73 \\
\hline $\begin{array}{l}\text { Life is too short to do work that makes you } \\
\text { postpone the pleasures life can provide }\end{array}$ & & & 0.55 \\
\hline Cronbach Alpha's for each scale & 0.86 & 0.72 & 0.60 \\
\hline
\end{tabular}

et al., (2005) recommendation for moderate $(0.6$ to $<0.7)$, good $(0.7$ to $<0.8)$ and very good $(0.8$ to $<0.9)$ reliabilities for scale design and measurement.

After having established reliable scales for measuring meaning, engagement and pleasure at work, the impact of these approaches on commitment and work satisfaction were established through the application of a regression analysis. The results of the regression analyses are presented in Figure 1 and Figure 2 below.

The results suggest that $21 \%$ of employee commitment is explained by a combination of the two variables meaning and engagement, both of which exhibit highly significant positive links $(<0.01)$. The results also suggest that $14 \%$ of job satisfaction is explained by a combination of all three variables, whereby only meaning and engagement exhibit significant positive links $(<0.01)$, and pleasure is linked negatively $(<0.05)$. 


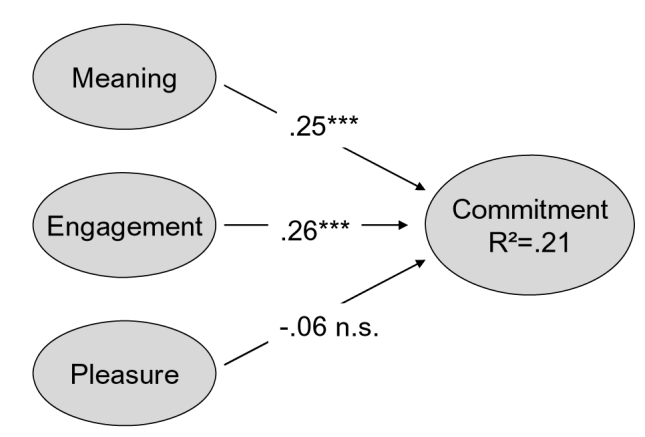

Figure 1: Regression analysis with commitment as outcome variable

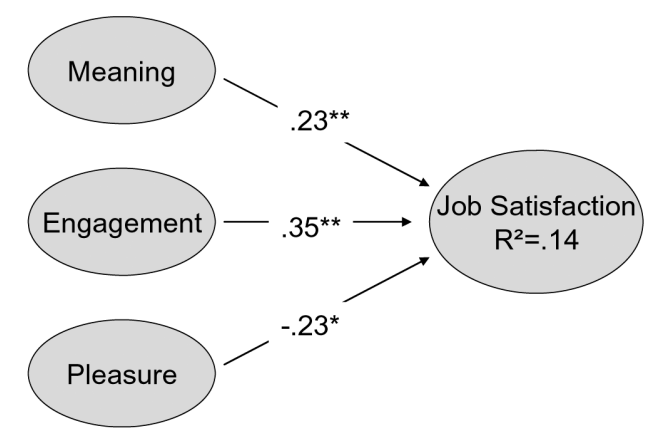

Figure 2: Regression analysis with job satisfaction as outcome variable $* * \star$ Significance found at the 0.001 level.

${ }^{*}$ Significance found at the 0.01 level.

* Significance found at the 0.05 level.

\section{Discussion}

The results of Study 1 show that it is possible to successfully adapt a positive psychology instrument from a life context to a work context. Moreover, it has been possible to link different approaches to work to positive organisational outcomes such as commitment and work satisfaction. The parallels between Seligman's work and the findings here are striking. In work it seems just as in life, meaning and engagement play larger roles than pleasure in bringing about positive outcomes. What is interesting here is that in this context these positive outcomes seem to be relevant both to organisations and individuals. Being able to pursue engagement and meaning in work not only brings about a satisfied employee but brings about one who is committed. Commitment has long been associated as one of the drivers of organisational success and performance (Meyer and Allen, 1997). The fact that the study has been conducted in many different organisations and countries adds validity to the findings suggesting that these approaches to work can be used equally well as instruments or metaphors for organisations to develop both happy and committed people. Of course, how organisations embrace these metaphors is not investigated. How organisations can most appropriately apply the positive psychology metaphor could offer fruitful avenues for future research. 
Once again the finding that pleasure is not positively connected to either commitment or job satisfaction poses an interesting quandary for organisations. It seems that the theorists who suggest that what matters in the 21st century is meaning and that people will seek meaning in their work may be right. The results also suggest that happy employees are more committed employees, suggesting that taking care of happiness also has benefits for a business.

\section{Study 2}

\section{Method and Results}

Seligman's thesis is that people who express and use their strengths more and people who find a balance between the demands of their lives and the use of their strengths will lead happier and more satisfied lives (Seligman, 2002). This study adapts Seligman's strengths and virtue questionnaire and applies it to the workplace. In doing so, the authors identify the strengths and virtues that are most in demand at work as well as those that are least required. The authors also highlight areas in which there are mismatches and matches between demands of work and the strengths and virtues of individuals. As such, this study shows managers key areas in which strengths and virtues could be leveraged more to enhance the expression and performance of individuals.

The results presented in the table below are drawn from a sub-sample of the participants in study 1 . In total 60 people participated in this part of the study. All were middle to senior managers working for 30 different private and public sector organisations in Western Europe. Results are presented in Table 3 below in three stages. In the first stage, there is a measure of the extent to which strengths and virtues are expressed in the workplace, by displaying the mean scores of strength in a descending rank order (column one). The second stage identifies the perceived match between people's strengths and the demands at the workplace (column two). The third stage shows areas in which there are opportunities to express strengths to a greater or lesser extent and thus opportunities for leveraging these strengths in the future (column three).

\section{Discussion}

While the sample size of this part of the study is relatively small, it is striking to notice the vast difference in the extent to which the strengths are expressed at work (mean scores range from 4.41 to 2.58). This is in contrast with Seligman's findings which suggest that the different strengths are expressed to similar levels across wider populations and wider life settings. This suggests that certain virtues and strengths are perceived to be more important to the nature and requirements of the workplace than others. The relatively low expression of spirituality, appreciation, love and valour is interesting. All of these are scoring lower than the midpoint on a five point scale. This paints a picture of work as a place in which the expression of virtues associated with a supportive community, so strongly advocated by Seligman, is not encouraged. The findings also show that this group of middle to senior managers believe that 
Table 3

\begin{tabular}{|c|c|c|c|}
\hline \multicolumn{2}{|c|}{$\begin{array}{l}\text { Expression of strengths at work } \\
\text { ("I express this strength a lot in my } \\
\text { work") }\end{array}$} & $\begin{array}{l}\text { Match between strength } \\
\text { and work demands } \\
\text { "“There is a match between } \\
\text { my strength and the } \\
\text { demands at work") }{ }^{2}\end{array}$ & $\begin{array}{l}\text { Demands at work require } \\
\text { to express more/less of } \\
\text { this strength than natural } \\
\text { inclination }\end{array}$ \\
\hline $\begin{array}{l}\text { 1. Integrity } \\
\text { 2. Judgment } \\
\text { 3. Perspective } \\
\text { 4. Fairness } \\
\text { 5. Perseverance } \\
\text { 6. Learning } \\
\text { 7. Leadership } \\
\text { 8. Zest } \\
\text { 9. Curiosity } \\
\text { 10. Intelligence } \\
\text { 11. Gratitude } \\
\text { 12. Citizenship } \\
\text { 13. Hope } \\
\text { 14. Playfulness } \\
\text { 15. Self-control } \\
\text { 16. Ingenuity } \\
\text { 17. Kindness } \\
\text { 18. Prudence } \\
\text { 19. Forgiveness } \\
\text { 20. Humility } \\
\text { 21. Valour } \\
\text { 22. Loving } \\
\text { 23. Appreciation } \\
\text { 24. Spirituality }\end{array}$ & $\begin{array}{l}M=4.41 \\
M=4.32 \\
M=4.23 \\
M=4.10 \\
M=4.05 \\
M=4.00 \\
M=3.98 \\
M=3.97 \\
M=3.90 \\
M=3.85 \\
M=3.68 \\
M=3.68 \\
M=3.66 \\
M=3.63 \\
M=3.59 \\
M=3.55 \\
M=3.37 \\
M=3.36 \\
M=3.32 \\
M=3.14 \\
M=2.98 \\
M=2.80 \\
M=2.68 \\
M=2.58\end{array}$ & $\begin{array}{l}\text { High match } \\
\text { High match } \\
\text { High match } \\
\text { High match } \\
\text { Medium match } \\
\text { Medium match } \\
\text { Medium match } \\
\text { High match } \\
\text { Medium match } \\
\text { Medium match } \\
\text { Medium match } \\
\text { Medium match } \\
\text { Medium match } \\
\text { Medium match } \\
\text { Medium match } \\
\text { Medium match } \\
\text { Medium match } \\
\text { Medium match } \\
\text { Medium match } \\
\text { Medium match } \\
\text { Medium match } \\
\text { Medium match } \\
\text { Low match } \\
\text { Medium match }\end{array}$ & \begin{tabular}{|l} 
more \\
more \\
more \\
\\
more \\
less \\
less \\
less \\
less \\
less \\
more \\
less \\
less \\
more \\
less \\
less \\
less \\
less \\
less \\
less
\end{tabular} \\
\hline
\end{tabular}

${ }^{1}$ Please note: The strengths are sorted by mean scores in descending order, measured on a fivepoint scale from $1=$ low expression to $5=$ high expression.

2 Please note: High match, medium match and low match established based on a five point scale whereby a score between 4 and 5 indicates a high match, a score between 3 and 4 indicates a medium match and a score below 3 indicates a low match.

3 Please note: Whether respondents express certain strengths more or less at work compared to their natural inclination by comparing the generic strength scores of individuals in the sample with their expression of these strengths at work in areas were respondents perceive a medium or low match.

their work demands high levels of integrity, judgement, perspective and fairness. It may well be the case that the corporate scandals of the past decade which displayed a failure of virtues such as integrity and judgement at the most senior level have heightened employees' awareness of the need for these particular virtues at work, but more research would need to be conducted to test this hypothesis.

Another area of interest is the match between people's strengths and the extent to which these are required at work. Nearly all the items have a high or medium match with only appreciation being a low match. Items that are medium in match may well provide fruitful avenues to pursue when considering how to improve the expression of strengths in working life. The next column provides an insight into which strengths are expressed more or less 
than their natural inclination. For items requiring more expression this requires individuals to go beyond their strengths and express what they can of a particular virtue in a particular situation. Most mismatches require individuals to suppress this strength in some way. The expression of gratitude, humility, kindness, playfulness, spirituality, citizenship and hope for example suggest that many of the human and community-based virtues are suppressed in the workplace. The rhetoric of a workplace in which community and meaning are valued seems to be exactly this: more of a rhetoric than a reality.

\section{Section 3}

\section{Conclusions and directions for future research}

In line with Seligman and Csikszentmihalyi's (2000) belief in the future growth of "a psychology of positive human functioning . . that achieves a scientific understanding and effective interventions to build thriving in individuals, families, and communities", the authors believe that the study of positive psychology in organisations will lead to a finer understanding of what drives and motivates employees to flourish and achieve their full potential at work. This paper suggests that employees' approach to work and understanding of their own potential can be usefully described and understood through the positive psychology lens - as it applies to the differentiation of the pleasurable, engaged and meaningful life, and the development of positive strengths and virtues. These positive emotions and traits and the approach to meaning, particularly in the context of the current experience of the "moral malaise", as Fineman (2005) calls it, in western consumerist societies are likely to contribute substantially to explanations of employee commitment, job satisfaction and overall happiness at work. Importantly, the development of this line of enquiry is predicated on the assumption that work is a part of individuals' lives and that feelings and behaviour within organisations cannot be studied in isolation of employees' overall approach to life and their wellbeing. Given many organisations' growing preoccupation and awareness of work-life balance and stress related burnout issues in post-industrial knowledge economies, this approach makes intuitive sense but will also, for the first time, begin to unravel how individuals interpret and make sense of their overall approach to life and wellbeing and how this directly impacts on organisational performance.

Initial findings suggest that elements of positive psychology seem to be relevant in the workplace. General approaches to life seem to provide useful ways to understand approaches to work, with approaches to work that involve meaning and engagement being of particular importance. This study goes beyond the theoretical work already done in organisational behaviour literature in that it brings much needed empirical evidence for the value of positive psychology to organisations and employees alike. In particular, the identification and measurement of different approaches and their resultant impact on work happiness and commitment may provide organisations with a valuable tool to improve their performance. Despite the relatively small sample size, the study of personal strengths and virtues also seems to have 
an impact at work. The paper uncovers some surprising findings despite the rhetoric of purpose and community at work: however, the work environment still seems a place where human virtues such as appreciation and kindness need to be suppressed. The findings provide a useful starting point and a potential instrument to analyse the strengths of individuals, the demands of work and potential to foster under-utilised strengths.

In adopting this approach to exploring the long term causes of happiness and the potential of positive characteristics in the workplace, the study also adds to the positive institutions pillar of positive psychology in that it provides an insight into how organisations can engender and support more positive behaviours from their employees and promote organisational growth and performance improvements. At a wider level this study makes a contribution to theorists such as Ryff (2003) who calls for positive psychology to successfully chart "the domain of human optimal functioning" in the context of the workplace and employee approaches to work.

\section{Suggestions for future research}

The studies described in this article have limitations which could be usefully addressed in future research. The generalisability of the studies would be improved if larger sample sizes were used and if the research was replicated in different sectors, in particular in traditional vocational fields such as health and education. Despite these limitations, the authors feel that the current studies are an important step towards developing further empirical research in positive psychology in relation to the workplace. Some possibilities for future research are listed below.

- What is the nature of the relationship between people's approach to life and their approach to work?

- Are there links between variables such as age, life experience, social class, income and job role and the different approaches to work that individuals follow?

- Are there links between the organisation's sector, the culture and the opportunities for career progression and the approaches to work that are predominant in an organisation?

- How does positive psychology connect to other well-established psychological concepts that have been seen to affect work, such as needs theory or drive theory?

- What is the interplay between positive psychology and other concepts relevant in organisational behaviour, such as staff morale, stress, turnover and engagement?

- How is positive psychology in the workplace linked to emotions at work?

- Can the positive psychology metaphor be used to provide insights into relationships that organisations have with other stakeholders? What are the applications of positive psychology to these relationships? Moreover, what are the consequent applications of positive psychology to the study of marketing, operations, supply chain management, investor relations, governance, corporate responsibility, sustainability and reputation? 


\section{References}

Cameron, K. S., Dutton, J. E. and Quinn, R. E. 'Foundations of positive organisational psychology', In: Cameron, K. S., Dutton, J. E. and Quinn, R. E. (Eds.), (2003), Positive organizational scholarship: Foundations of a new discipline, San Francisco: Berrett-Koehler.

Fineman, S. (2006), 'On Being Positive: Concerns and Counterpoints', Academy of Management Review, Vol. 31, No. 2, pp. 270-291.

Gable, S. L. and Haidt, J. (2005), 'What (and Why) is Positive Psychology?', Review of General Psychology, Vol. 9, No. 2, pp. 103-110.

Hair, J. F., Babin, B., Money, A. and Samouel, P. (2003), Essentials of Business Research Methods, Chichester, West Sussex, UK: Wiley.

Luthans, F. (2002), 'Positive organisational behaviour: Developing and managing psychological strengths', Academy of Management Executive, Vol. 16, No. 1, pp. 57-72.

Lyubomirsky, S., King, L. and Diener, E. (2005), 'The Benefits of Frequent Positive Affect: Does Happiness Lead to Success?', Psychological Bulletin, Vol. 131 Issue 6, pp. 803-855.

Maslow, A. H. (1954), Motivation and personality, New York: Harper and Row.

Maslow, A. H. (1971), The farther reaches of human nature, New York: Viking Press.

Meyer, J. P. and Allen, J. A. (1997), Commitment in the workplace: theory, research and application, London: Sage.

Park, N., Peterson, C. and Seligman, M. E. P. (2004), 'Strengths of character and well-being', Journal of Social and Clinical Psychology, Vol. 23, No. 5, pp. 603-619.

Park, N., Peterson, C. and Seligman, M. E. P. (2005a), Character strengths in forty nations and fifty states, Unpublished manuscript, University of Rhode Island.

Park, N., Peterson, C. and Seligman, M. E. P. (2005b), Strengths of character and well-being among youth, Unpublished manuscript, University of Rhode Island.

Peterson, C. and Seligman, M. E. P. (2004), Character strengths and virtues: A handbook and classification, Washington, DC: American Psychological Association.

Peterson, C., Park, N. and Seligman, M. E. (2005b), 'Orientations to happiness and life satisfaction: The full life versus the empty life', Journal of Happiness Studies, 6, pp. 25-41.

Roberts, L. M. (2006). Shifting the lens on organisational life: the added value of positive scholarship. Academy of Management Review, Vol. 31, No. 2, pp. 292-305.

Ryff, C. D. (2003), 'Corners of myopia in the positive psychology parade', Psychological Inquiry, Vol. 14, pp. 153-159.

Seligman, M. E. P. (1999), 'The president's address', American Psychologist, 54, pp. 559-562.

Seligman, M. E. P. and Csikszentmihalyi, M. (2000), ,Positive Psychology: An Introduction', American Psychologist, Vol. 55, No. 1, pp. 5-14.

Seligman, M. E. P. (2002), Authentic Happiness: Using the new positive psychology to realize your potential for lasting fulfillment, London: Brealey.

Seligman, M. E. P. and Pawelski, J. O. (2003), 'Positive psychology: FAQs', Psychological Inquiry, Vol. 14, No. 2, pp. 159-169.

Seligman, M. E. P., Steen, T. A., Park, N. and Peterson, C. (2005), 'Positive Psychology Progress: Empirical Validation of Interventions', American Psychologist, Vol. 60, No. 5, pp. 410-421.

Kevin Money is Associate Professor at Henley Business School, Director of The John Madejski Centre for Reputation and editor of The Journal of General Management. Kevin has overall responsibility for direction in governance, reputation and relationships and his areas of expertise include leadership, organisational reputation and relationships, corporate social responsibility, governance and sustainability. Kevin received his PhD from Henley and is a Chartered Psychologist. He has acted as a consultant to major companies and voluntary organisations in the UK, USA and South Africa and is also a Fellow of the Sunningdale Institute, a think-tank that is part of the National School of Government.

Carola Hillenbrand is the Subject Area Leader for Reputation and Relationships at Henley Business School. Her key areas of professional expertise are corporate reputation and responsibility, and the psychological foundations of successful relationships. Carola is also the Lead Researcher at the John Madejski Centre for Reputation, overseeing a variety of large- 
scale research projects in the profit and not-for-profit sector. She teaches statistics and multivariate data analysis on both the MBA and the doctoral programme. Carola received her Masters degree in Psychology from the Justus-Liebig Universität of Giessen (Germany) and her $\mathrm{PhD}$ from Brunel University, London.

Nuno da Camara is Client Relationship Director of the John Madejski Centre for Reputation and a PhD Research Fellow at Henley Business School. His main area of interest is in the role of emotions and wellbeing in organisational culture and its impact on corporate reputation and stakeholder behaviour. Nuno has a background in corporate communications for the financial and professional services sector having worked in-house for Aviva, Clifford Chance and the European Banking Federation; and for a variety of blue chip companies in a consultancy capacity. Nuno has a Masters in European Studies from the London School of Economics and Political Science, as well as bachelors degrees in psychology, and history. 